\title{
Evaluation of left ventricular function: does the imaging technique matter?
}

\author{
Leo H. B. Baur
}

Received: 27 June 2008/ Accepted: 30 June 2008/Published online: 24 July 2008

(C) The Author(s) 2008

Measurement of left ventricular ejection fraction is a common procedure in cardiology. This is not without reason. Left ventricular ejection fraction has proven to be an important predictor of mortality in patients with heart failure and after myocardial infarction [1,2]. It is also frequently used to monitor left ventricular remodelling after myocardial infarction and to select patients for ICD therapy and biventricular pacing [3, 4].

Next to this, measurement of left ventricular ejection fraction is used to detect cardiac toxicity in cancer treatment, especially chemotherapy with anthracyclines and related compounds (doxorubicin, daunorubicin, idarubicin, epirubicin, anthraquinone mitoxantrone) and trastuzumab [5, 6]. Therefore determination of left ventricular ejection fraction has to be correct and reproducible. Fortunately, several techniques are available to measure left ventricular ejection fraction: echocardiography, nuclear imaging, magnetic resonance imaging, CT of the heart and contrast angiography. Echocardiography is the most commonly used technique, particularly because it is a cheap and easy to perform technique, gives no irradiation gives no patient discomfort and can be used anywhere. In addition, the technique can be used in settings where MRI cannot be used and in patient with irregular heart

L. H. B. Baur ( $ه)$

Department of Cardiology, Atrium Medical Centre

Parkstad and University of Maastricht, Henri Dunantstreet 5 , 6401CX Heerlen, The Netherlands

e-mail: 1.baur@atriummc.nl rhythm, which makes radionuclide angiography inaccurate. Unfortunately the technique is highly operator dependent and patient dependent. Left ventricular function is frequently measured with $2 \mathrm{D}$ techniques with extrapolation to a 3D structure, assuming, that the four chamber view and two chamber view give a correct display of this 3D structure. In this setting, visual assessment may not always be accurate [7, 8]. Intra observer and inter observer variability improves if quantitative assessment with the Simpson's rule is used. In some patients echocardiography is technically cumbersome (Patients with pulmonary disease, women with large breasts and patients with deformations of the thorax). Contrast enhancement can improve estimates of left ventricular ejection fraction significantly in this setting [9]. Magnetic resonance imaging gives also no radiation exposure, but is more difficult to perform and more expensive. Because of the high resolution of the images, the high endocardial intrinsic contrast, the absence of foreshortening, the absence of user-dependence, the high reproducibility, the ability to perform $3 \mathrm{D}$ images and the moderate to high temporal resolution, MRI has become the gold standard for the last two decades [10]. Nuclear imaging, CT of the heart and contrast angiography give radiation exposure, and are therefore contraindicated in pregnant women, are relative expensive and require contrast agents $(\mathrm{CT}$ and contrast angiography) with possible adverse effects. Radionuclide ventriculography was introduced three decades ago and soon became an accepted technique for measurement of left ventricular ejection fraction. This 
with a high degree of reproducibility [11]. The advantage is, that measurements do not rely on geometric assumptions regarding the shape of the left ventricle and that the patient's body habitus does not limit the technique [12]. The technique is performed by labeling the patient's red blood pool with a radioactive tracer (mostly technetium 99m) and measuring radioactivity over the chest with a gamma camera, as the radioactive blood flows through the heart. Gated single photon emission tomography (SPECT) myocardial perfusion imaging permits simultaneous assessment of ventricular perfusion and function. It has been compared with echocardiography and MRI and was closely correlated [13]. Left ventricular function with cardiac CT can be acquired within $10-15 \mathrm{~s}$. The technique is very reproducible, as there is usually very good delineation of the endocardial border of all myocardial walls [14]. Unfortunately, the technique requires a considerable radiation exposure.

Are these techniques equal and can they be exchanged? The current paper of Gimelli et al. [15] throws some light on this issue. The authors show, that measurements of left ventricular ejection fraction with echocardiography, radionuclide imaging and contrast angiography are closely related to each other. All imaging methods gave prognostic information about mortality in this study. Although the relationship between the three methods was very close, individual measurements with different techniques could obscure the real situation. Both echocardiography and gated SPECT tended to overestimate angiographic measurements at the lowest values of LVEF and underestimated angiographic measurements at the highest value of LVEF. Differences between the techniques can be explained by the difference in image building (3D acquisition in nuclear techniques and 2D techniques with echocardiography and contrast angiography). And the sampling of a large number of heart beats in SPECT imaging and a limited number of images with echocardiography and contrast angiography. Possibly the negative inotropic effect of contrast give an additional explanation of these findings. The techniques would be more exchangeable if only 3D imaging (3D echo, MRI, CT and SPECT) are used, with data acquisition over several heart beats.

Selection of a proper technique to detect left ventricular dysfunction, select patients for ICD or biventricular pacing and guide chemotherapy depends on the experience of the imaging lab, the patient characteristics (COPD or atrial fibrillation) and the availability of the technique in the hospital. If for one patient a specific technique has been chosen, this patient has to be imaged with the same technique during follow-up to avoid artificial improvement or deterioration of ventricular function. 3D techniques are preferred for this.

Some guidelines, could be [12]:

Radionuclide ventriculography, Cine MRI or 2D/3D echocardiography with quantitative measurement of left ventricular ejection fraction should be used for serial measurements of left ventricular ejection fraction or when critical management decisions depend upon the actual numeric value of the LVEF, such as when to place an implantable cardioverter-defibrillator, when to perform surgery in patients with asymptomatic mitral regurgitation, or whether chemotherapy is contraindicated in a patient with cancer.

2D echocardiography is the preferred technique for routine assessment of left ventricular ejection fraction in patients with coronary disease and valvular heart disease. One has to realise, that visual assessment may not always be accurate. If the echocardiographic image quality is suboptimal, one should switch to radionuclide angiography or cine-MRI. Gated SPECT myocardial perfusion nuclear imaging on the other hand is preferred for simultaneous assessment of myocardial perfusion and function in patients with suspected coronary artery disease.

Open Access This article is distributed under the terms of the Creative Commons Attribution Noncommercial License which permits any noncommercial use, distribution, and reproduction in any medium, provided the original author(s) and source are credited.

\section{References}

1. Lee KL, Pryor DB, Pieper KS, Harrell FE Jr, Califf RM, Mark DB, Hlatky MA, Coleman RE, Cobb FR, Jones RH (1990) Prognostic value of radionuclide angiography in medically treated patients with coronary artery disease. A comparison with clinical and catheterization variables. Circulation 82(5):1705-1717

2. Wong M, Staszewsky L, Latini R, Barlera S, Glazer R, Aknay N, Hester A, Anand I, Cohn JN (2004) Severity of left ventricular remodeling defines outcomes and response to therapy in heart failure: valsartan heart failure trial (Val-HeFT) echocardiographic data. J Am Coll Cardiol 43(11):2022-2027

3. Baur LHB, Schipperheyn JJ, Van der Velde E, Reiber J, Van Dijkman PRM, Gerrittsen G, Van Eck-Smit B, Voogd PJ, 
Van der Wall EE, Bruschke AVG (1996) Reproducibility of left ventricular size, shape and mass with echocardiography, magnetic resonance imaging and radionuclide angiography in patients with anterior wall infarction: a plea for Core Laboratories. Int J Card Imaging 12:233-240

4. Bardy GH, Lee KL, Mark DB, Poole JE, Packer DL, Boineau R, Domanski M, Troutman C, Anderson J, Johnson G, McNulty SE, Clapp-Channing N, Davidson-Ray LD, Fraulo ES, Fishbein DP, Luceri RM, Ip JH (2005) Amiodarone or an implantable cardioverter-defibrillator for congestive heart failure. N Engl J Med 352(3):225-237

5. Yeh ET, Tong AT, Lenihan DJ, Yusuf SW, Swafford J, Champion C, Durand JB, Gibbs H, Zafarmand AA, Ewer MS (2004) Cardiovascular complications of cancer therapy: diagnosis, pathogenesis, and management. Circulation 109(25):3122-3131

6. Keefe DL (2002) Trastuzumab-associated cardiotoxicity. Cancer 95(7):1592-1600

7. Domanski MJ, Nanda N (2006) Echocardiographic determination of left ventricular function. J Am Soc Echocardiogr 19:941-942

8. Gottdiener J, Bednarz J, Devereux R, Gardin J, Klein A, Manning WJ, Morehead A, Kitzman D, Oh J, Quinones M, Schiller NB, Stein JH, Weissman NJ (2004) American Society of Echocardiography recommendations for use of echocardiography in clinical trials: a report from the american society of echocardiography's guidelines and standards committee and the task force on echocardiography in clinical trials. J Am Soc Echocardiogr 17:1086-1119

9. Hundley W, Kizilbash A, Afridi I, Franco F, Peshock R, Grayburn P (1998) Administration of an intravenous perfluorocarbon contrast agent improves echocardiographic determination of left ventricular volumes and ejection fraction: comparison with cine magnetic resonance imaging. J Am Coll Cardiol 32:1426-1432

10. Biederman RWW (2008) Left and right ventricular structure and function. In: Biederman RWW, Doyle M, Yamrozik J (eds) Cardiovascular MRI Tutorial. Wolters Kluwer. Chapter 8, pp 84-92

11. Wackers FJ, Berger HJ, Johnstone DE, Goldman L, Reduto LA, Langou RA, Gottschalk A, Zaret BL (1979) Multiple gated cardiac blood pool imaging for left ventricular ejection fraction: validation of the technique and assessment of variability. J Cardiol 43(6):1159-1166

12. Danias PG, Heller GV (2008) Noninvasive methods for measurement of left ventricular systolic function Uptodate 16.1

13. Ioannidis JP, Trikalinos TA, Danias PG (2002) Electrocardiogram-gated single-photon emission computed tomography versus cardiac magnetic resonance imaging for the assessment of left ventricular volumes and ejection fraction: a metaanalysis. J Am Coll Cardiol 39:2059-2068

14. Koch K, Oellig F, Oberholzer K, Bender P, Kunz P, Mildenberger P, Hake U, Kreitner KF, Thelen M (2005) Assessment of right ventricular function by 16-detectorrow CT: comparison with magnetic resonance imaging. Eur Radiol 15(2):312-318

15. Gimelli A, Landi P, Sicari R, Frumento P, L'Abbate, Roval D (2008) Left ventricular ejection fraction measurements: accuracy and prognostic implications in a large population of patients with known or suspected ischemic heart disease. Int J Cardiovasc Imaging. doi:10.1007/s10554-008-9317-1 